\title{
Knowledge of stroke risk factors among the patients with previous stroke or transient ischemic attack in a tertiary care hospital of Bangladesh
}

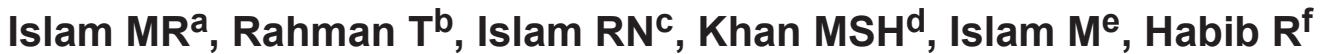

\begin{abstract}
Background: Patients of stroke or transient ischaemic attacks (TIA) are at risk of further stroke. Our objective was to study patients admitted with stroke/TIA regarding their knowledge about risk factors for having anew event of stroke/TIA, possible associations between patient characteristics and patients 'knowledge about risk factors, and patients'knowledge about their preventive treatment for stroke/TIA.

Methods: A questionnaire was used for 200 patients with stroke/TIA diagnoses. We asked 13 questions about diseases/conditions and lifestyle factors known to be risk factors and four questions regarding other diseases/ conditions ("distractors"). Additional questions concerned with the patients'social and functional status and their drug use were asked. Categorical variables were analyzed using chi square test, while one-way analysis of variance and univariate analysis of variance were used for continuous variables. Logistic regression was employed to describe risk. A p value of, $p<0.05$ was considered statistically significant.

Results: The risk factors that were most often identified by the patients were Diabetes(75.9\%), hypertension $(83.3 \%)$, previous stroke or TIA $(81.5 \%)$, smoking $(85.2 \%)$, regular exercise $(75.9 \%)$, older age $(83.3 \%)$, overweight (75.9\%) and patients with ischemic heart disease (70.4\%). Atrial fibrillation and carotid stenosis were identified by less than $50 \%$ of the patients. $44.5 \%$ of the patients could identify 10 or more stroke/TIA risk factors. We observed that higher age, having a diagnosis of cerebral infarction/TIA, patients residing in urban area, high income group, businessman/retired service holder, family history of cardiovascular disease, past history of stroke / TIA were related to better knowledge of stroke/TIA risk factors. Anticoagulants and antiplatelets are important drugs for stroke/TIA prevention but only 20(9.3\%) of the patients who reported anticoagulants and 76(35.2\%) of the patients taking these drugs marked them as intended for prevention.

Conclusion: Knowledge about diabetes, hypertension and smoking as risk factors was good, and patients who suffered from atrial fibrillation or carotid stenosis seemed to be less informed about these conditions as risk factors. The knowledge level was low regarding the use of anticoagulants and antiplatelets for stroke/TIA prevention. Better patient educational strategies for stroke/TIA patients should be developed. Furthermore, individuals with less knowledge should be given special consideration when developing strategies and programmes thus improving awareness of stroke risk factors.
\end{abstract}

Key words: stroke, transient ischemic attacks, knowledge, risk factors.

(BIRDEM Med J 2021; 11(1): 22-29)

Author information

a. Md. Rashedul Islam, Assistant Professor, Department of Neurology, BIRDEM General Hospital, Dhaka, Bangladesh.

b. Tanbin Rahman, MD Thesis part student (Hematology), Dhaka Medical College, Dhaka, Bangladesh.

c. Rafi Nazrul Islam, Senior Medical Officer, Nephrology, BIRDEM General Hospital, Dhaka, Bangladesh.

d. Mohammad Sakhawat Hossen Khan, Registrar, Department of Neurology, BIRDEM General Hospital, Dhaka, Bangladesh.

e. Mofizul Islam, Senior Medical officer, Department of Neurology, BIRDEM General Hospital, Dhaka, Bangladesh.

f. Rumana Habib, Associate professor, Department of Neurology, BIRDEM General Hospital, Dhaka, Bangladesh.

Address of correspondence: Md. Rashedul Islam, Assistant Professor, Department of Neurology, Room-1420, 13 ${ }^{\text {th }}$ Floor, BIRDEM General Hospital, Shahbag, Dhaka-1000, Dhaka, Bangladesh. Email: rashed2k2001 @yahoo.com

Received: June 28, 2020

Revision received: July 29, 2020

Accepted: October 31, 2020 


\section{INTRODUCTION}

Stroke is the leading cause of disability in the Asian population. ${ }^{1,2}$ It becomes important health problem for Bangladesh as more than $25 \%$ of its population live below the poverty line. ${ }^{3}$ A large number of preventable deaths in Bangladesh occur due to stroke. ${ }^{4,5}$ Individuals in Bangladesh having age of 40 years or more have a stroke prevalence of $0.3 \%$ and its prevalence increases to $1 \%$ in individuals aged 70 years or more. ${ }^{5}$ Risk factors for stroke in Bangladesh include hyperlipidemia, diabetes mellitus, heart disease, cigarette smoking, and previous history of TIA. ${ }^{6,7}$ Bangladesh due to its large population lacks the requisite health infrastructure and trained human resource needed to deal with the high burden of stroke. ${ }^{8}$ Prevention of stroke is crucial for all, as individuals who have suffered a previous stroke are at increased risk of recurrence ${ }^{9,10}$; hence secondary prevention becomes a major concern. Recurrent stroke, although known to be characterized by greater level of mortality and morbidity compared to first-ever stroke, is preventable. ${ }^{11,}{ }^{12}$ Many reports have shown that secondary prevention after stroke or TIA is not satisfactory. ${ }^{13-15}$ One of the reasons for unsatisfactory secondary prevention could be patients' lack of knowledge about risk factors for suffering stroke, which was suggested as a contributing factor to the lack of compliance with medical advice and treatment. ${ }^{16}$ Some previous studies have demonstrated poor understanding of stroke risks and symptoms among general people. ${ }^{17-}$ ${ }^{20}$ Some studies showed that knowledge about stroke and stroke risk factors was poorest among groups at highest risk of suffering from stroke. ${ }^{21,22}$ Further, a few studies assessing stroke or TIA patients'knowledge about stroke risk factors have indicated poor knowledge about stroke, including knowledge about risk factors some months after stroke. ${ }^{15}$ Our objective was to study primary health care patients who have already suffered from stroke or Transient ischemic attack (TIA) regarding their knowledge about risk factors for having a new event of stroke/TIA, possible associations between patient characteristics and patients' knowledge about risk factors and their knowledge about their own treatment for stroke/TIA prevention. Improvement of knowledge of stroke risk factors among patients may be an effective means of achieving prevention. This is particularly important in making feasible policies to enhance knowledge and consequently aid in effective prevention of recurrent stroke.

\section{METHODS}

Study design: A cross-sectional study

Study population: This study was carried out in Department of Neurology, BIRDEM General Hospital from January, 2019- Dececember, 2019.Two hundred consenting stroke survivors participated in the study. Patients with previous stroke (Ischemic stroke and cerebral hemorrhage)/TIA, $\geq 18$ years of age were consecutively and purposively selected for the study. Patients with cognitive impairment were excluded from the study. Subarachnoid hemorrhage and venous infarction, which are considered as a stroke subtypes, but was excluded due to different aetiology and risk factors.

\section{Questionnaire}

A questionnaire was used to assess the patients' knowledge about diseases and conditions established as important factors increasing the risk of having a new stroke/ TIA. Patients were asked to evaluate how 13 diseases/conditions, established as stroke/TIA risk factors, influenced the risk of having a new stroke/TIA. The risk factors were presented in the questionnaire in the following order: higher age, hyperlipidemia, diabetes, a family history of cardiovascular disease, atrial fibrillation, hypertension, overweight, regular physical exercise, excessive alcohol consumption, previous stroke/TIA, carotid stenosis, smoking and ischaemic heart disease. The questionnaire was designed as a series of questions about stroke/TIA risk factors with the same response alternatives.

To reduce this risk of giving the same answer to each question without really considering it, four

Questions regarding medical diagnoses/conditions which are known not to be stroke/TIA risk factors ("distractors") were added: rheumatoid arthritis, osteoporosis, thyroid disease and allergy. An example of a question was: "How do you think that diabetes influences the risk of having a new stroke/TIA?" Possible answers were: "it increases the risk", "it reduces the risk", "it does not influence the risk", "do not know". We considered "increases the risk" to be the correct

answer for questions about stroke/TIA risk factors, except for the question about regular exercise habits, where "reduces the risk" was considered to be correct. The correct answer for the distractors was "does not influence the risk". 
Patients were also asked if they regarded the disease/ condition in the questionnaire as their own; for example, "Do you have diabetes?" with the following response alternatives: "yes", "no", "do not know". For questions concerning lifestyle factors (overweight, level of physical activity, alcohol consumption, smoking) we asked the patients to add self-reported information to their answers about their weight and height (from which Body Mass Index, BMI was calculated), exercise habits, alcohol and tobacco use. Finally the patients were asked to list all the drugs they were taking and to mark those which they considered to be prescribed for preventing new events of stroke/TIA. ${ }^{29}$

\section{Data analysis}

The main outcome measure of the study was the extent to which patients could correctly identify the different stroke/TIA risk factors in the questionnaire. Only the answer "it increases the risk" was considered to be correct (except for the question about regular exercise habits, which was constructed in the opposite way: "How do you think that regular exercise influences the risk of having a new stroke or TIA?" and where the correct answer was "it reduces the risk"). We also calculated each patient's knowledge about stroke/TIA risk factors, defined as the number of correctly identified stroke/TIA risk factors in the questionnaire(range 0-13). The patients' knowledge about their own treatment for stroke/ TIA prevention was assessed by reviewing the patients' ability to mark, in their self-reported lists, the drugs which they thought were prescribed to prevent new events of stroke or TIA. The dependent variable (the number of correctly identified risk factors) was then categorized for the purpose of statistical analysis. We defined "good" and "poor" knowledge of stroke/TIA risk factors according to the distribution of percentiles of correct answers. This resulted incut-off points of less than 8 correct answers, which were categorized as poor knowledge; and more than 11 correct answers, which was categorized as good knowledge. The group with an intermediate number of correct answers (8-11) was categorizedas having "moderate" knowledge.

\section{Statistical analyses}

All data were entered into a database and this was exported to statistical software (SPSS Inc, version 20) for analysis. Descriptive statistics such as mean, standard deviation, frequency, median, range and percentage were used to express data. Categorical variables were analyzed using chi square test, while one-way analysis of variance and univariate analysis of variance were used for continuous variables. Logistic regression was employed to describe risk. A $p$ value of, $p<0.05$ was considered statistically significant.

\section{RESULTS}

Majority of the patients in the study population were $51-70$ years age group (78\%), and 126 patients $(63.0 \%)$ were men. Cerebral infarction was registered as diagnosis for 146 patients $(73 \%)$ followed by TIA (14.5\%) and intracerebral hemorrhage (12.5\%). Higher proportion of the patients belonged to higher BMI (61\%) group, living in urban area $(60 \%)$ and a higher proportion of patients had low educational level (62\%). Current smoker is reported in 68 patients $(31.5 \%)$ and tobacco chewer in 48 patients $(22.2 \%) .108$ patients belonged to stressful work environment group (62.8\%). Other lifestyle and social factors are described in Table I.

\section{Patients' identification of stroke/TIA risk factors}

The risk factors that were most often identified by the patients were Diabetes(75.9\%), hypertension(83.3\%), previous stroke or TIA(81.5\%), smoking(85.2\%), regular exercise(75.9\%), older age(83.3\%), overweight $(75.9 \%)$ and ischemic heart disease (70.4\%) Table II. Atrial fibrillation and carotid stenosis were identified by less than $50 \%$ of the patients. The proportion of incorrect answers, i.e. where the patients answered that the risk factor "does not influence" or "reduces" the risk (for exercise habits "increases" instead of "reduces"), was generally low. Few patients considered medical conditions that were not stroke/ TIA risk factors (distractors) as stroke/ TIA risk factors (Table II). The most common answer was "do not know", although there was a group of patients who stated that these conditions did not affect the risk of having a new event of stroke/TIA (9.3\% for osteoporosis, $33.3 \%$ for allergy, $18.3 \%$ for rheumatoid arthritis and $11.1 \%$ for thyroid disease). $44.5 \%$ of the patients could identify 10 or more stroke/TIA risk factors. A frequency histogram with the proportions of patients who correctly identified different numbers of stroke/TIA risk factors is shown in Figure 1. 
Table I Stroke/TIA related diagnosis and patient characteristics

\begin{tabular}{lc}
\hline Age (years) & $\mathrm{n}(\%)$ \\
\hline $31-50$ & $20(10.0 \%)$ \\
$51-70$ & $156(78.0 \%)$ \\
$71-90$ & $24(12.0 \%)$ \\
\hline Sex & $\mathrm{n}(\%)$ \\
\hline Male & $126(63.0 \%)$ \\
Female & $74(37.0 \%)$ \\
Stroke Related Diagnoses & $\mathrm{n}(\%)$ \\
Cerebral infarction & $146(73.0 \%)$ \\
Intracerebralhaemorrhage & $25(12.5 \%)$ \\
Transient ischaemic attack & $29(14.5 \%)$ \\
Life style factors & \\
\hline BMI (kg/m $\left.{ }^{2}\right)$ & $\mathrm{n}(\%)$ \\
\hline$\leq 25$ (kg/m $\left.{ }^{2}\right)$ & $122(61.0 \%)$ \\
$<25$ (kg/m $\left.{ }^{2}\right)$ & $78(39.0 \%)$ \\
Alcohol Consumption & $\mathrm{n}(\%)$ \\
Alcohol intake & $12(5.6 \%)$ \\
\hline Tobacco Consumption & $\mathrm{n}(\%)$ \\
\hline Tobacco Chewer & $48(22.2 \%)$ \\
Current Smoker & $68(31.5 \%)$ \\
Former Smoker & $32(14.8 \%)$ \\
Address & $\mathrm{n}(\%)$ \\
Rural & $80(40.0 \%)$ \\
Urban & $120(60.0 \%)$ \\
\hline Physical Activity Level & $\mathrm{n}(\%)$ \\
\hline Sedentary (<30 min/24 h) & $68(32.7 \%)$ \\
Mild (30-59 min/24 h) & $72(34.6 \%)$ \\
Moderate (60-90 min/24 h) & $52(25.0 \%)$ \\
High (>90 min/24 h) & $16(7.7 \%)$ \\
\hline Work status & $\mathrm{n}(\%)$ \\
\hline Labour Work & $20(9.3 \%)$ \\
Unskilled worker & $12(5.6 \%)$ \\
Agriculture & $8(3.7 \%)$ \\
Housewife & $80(37.0 \%)$ \\
Business & $52(26.0 \%)$ \\
Sedentary Work & $20(9.3 \%)$ \\
Office job (Public sector) & $8(3.7 \%)$ \\
\hline & $8(3.7 \%)$ \\
\hline & $4(1.9 \%)$ \\
Skilled worker & \\
\hline
\end{tabular}

\begin{tabular}{lc}
\hline Work Place Environment & $\mathrm{n}(\%)$ \\
\hline Not stressful & $64(37.2 \%)$ \\
Stressful & $108(62.8 \%)$ \\
\hline Monthly Income & $\mathrm{n}(\%)$ \\
\hline$<20,000$ Taka & $104(56.5 \%)$ \\
$>20,000$ Taka & $80(43.5 \%)$ \\
\hline Education Level & $\mathrm{n}(\%)$ \\
\hline SSC or below & $124(62.0 \%)$ \\
HSC or above & $76(38.0 \%)$ \\
HSC & $20(10.0 \%)$ \\
Graduate & $40(20.0 \%)$ \\
Postgraduate & $16(8.0 \%)$ \\
\hline Dependency on Aid & $\mathrm{n}(\%)$ \\
\hline Dependent on Aid & $68(32.1 \%)$ \\
Cane & $12(5.7 \%)$ \\
Crutch & $32(15.1 \%)$ \\
Walker & $24(11.3 \%)$ \\
Not needed & $144(67.9 \%)$ \\
\hline
\end{tabular}

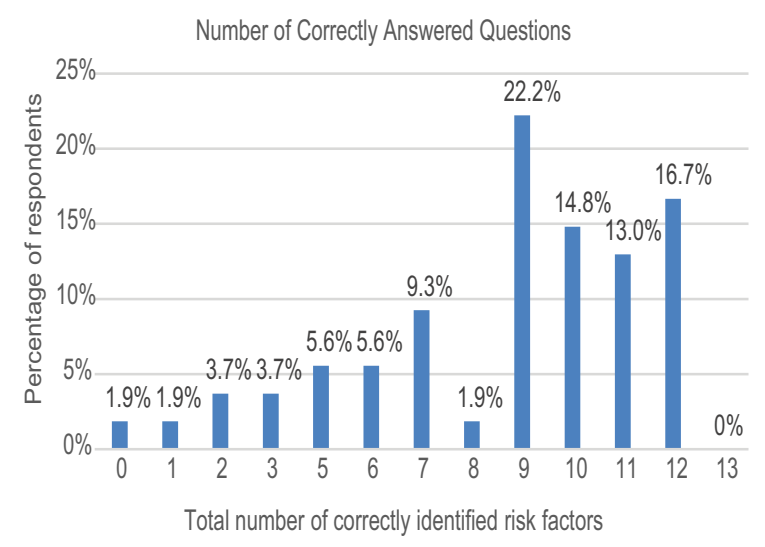

Figure 1 Proportion of patients who could correctly identify different numbers of stroke/TIA risk factors 
Table II Proportion (\%) of patients considering diseases/conditions to be or not to be stroke/TIA risk factors

\begin{tabular}{|c|c|c|c|c|}
\hline & $\begin{array}{c}\text { Increases the } \\
\text { risks, } \mathrm{n}(\%) \\
\mathrm{n}(\%)\end{array}$ & $\begin{array}{l}\text { Reduces } \\
\text { the risks, } \\
\text { risks, } \mathrm{n}(\%)\end{array}$ & $\begin{array}{c}\text { Does not } \\
\text { influence the } \\
\mathrm{n}(\%)\end{array}$ & $\begin{array}{l}\text { I do not } \\
\text { know, }\end{array}$ \\
\hline 1. Diabetes & $164(75.9 \%)$ & & $12(5.6 \%)$ & $40(18.5 \%)$ \\
\hline 2. High blood pressure & $180(83.3 \%)$ & & $8(3.7 \%)$ & $28(13.0 \%)$ \\
\hline 3. Dyslipidaemia & $4(1.9 \%)$ & & $60(27.8 \%)$ & $152(70.4 \%)$ \\
\hline 4. Carotid stenosis & $92(42.6 \%)$ & & $4(1.9 \%)$ & $120(55.6 \%)$ \\
\hline 5. Atrial fibrillation & $92(42.6 \%)$ & & $16(7.4 \%)$ & $108(50.0 \%)$ \\
\hline 6. Suffering previous stroke / TIA & $176(81.5 \%)$ & $4(1.9 \%)$ & $4(1.9 \%)$ & $32(14.8 \%)$ \\
\hline 7. Ischaemic heart disease & $152(70.4 \%)$ & & $4(1.9 \%)$ & $60(27.8 \%)$ \\
\hline 8. Smoking & $184(85.2 \%)$ & & $4(1.9 \%)$ & $28(13.0 \%)$ \\
\hline 9. Excessive alcohol consumption & & & $52(24.1 \%)$ & $164(75.9 \%)$ \\
\hline 10. Regular exercise & $4(1.9 \%)$ & $164(75.9 \%)$ & $8(3.7 \%)$ & $40(18.5 \%)$ \\
\hline 11. Overweight & $164(75.9 \%)$ & & $8(3.7 \%)$ & $44(20.4 \%)$ \\
\hline 12. Older age & $180(83.3 \%)$ & & $8(3.7 \%)$ & $28(13.0 \%)$ \\
\hline $\begin{array}{l}\text { 13. Family history of cardiovascular disease } \\
\text { Distractors }\end{array}$ & $136(63.0 \%)$ & & $20(9.3 \%)$ & $60(27.8 \%)$ \\
\hline 14 a. Osteoporosis & $36(16.7 \%)$ & & $20(9.3 \%)$ & $160(74.1 \%)$ \\
\hline 14 b. Allergy & $12(5.6 \%)$ & & $72(33.3 \%)$ & $132(61.1 \%)$ \\
\hline $14 \mathrm{c}$. Rheumatoid arthritis & $20(9.3 \%)$ & & $40(18.5 \%)$ & $156(72.2 \%)$ \\
\hline $14 \mathrm{~d}$. Thyroid disease & $40(18.5 \%)$ & & $24(11.1 \%)$ & $152(70.4 \%)$ \\
\hline
\end{tabular}

Associations between patient characteristics and patients' knowledge about risk factors

After performing an ordered logistic regression analysis, we observed that higher age(OR 1.053; 95\% CI 1.007 - 1.10), having a diagnosis of cerebral infarction/ TIA(OR 4.63; $95 \%$ CI 1.485 - 14.481), patients residing in urban are(OR 5.266; 95\% CI $1.864-14.875)$, high income group(OR 6.477; 95\% CI 2.21-18.91), businessman/retired service holder(OR 6.05; 95\% CI 1.44 - 25.47),Family history of cardiovascular disease(OR 4.60; 95\% CI 1.83 - 11.52), Past history of stroke / TIA (OR 8.87; 95\% CI 2.62 - 29.94) or living alone (OR 0.490; 95\% CI 0.241 - 0.997) were related to better knowledge of stroke/TIA risk factors (Table III).

Table III Number and proportion of patients who reported taking drugs and listing them as intended for stroke/ TIA prevention

\begin{tabular}{lcccc}
\hline & $\begin{array}{c}\text { Taking for } \\
\text { Prevention }\end{array}$ & $\begin{array}{c}\text { Taking for } \\
\text { Treatment }\end{array}$ & $\begin{array}{c}\text { Not taking } \\
\text { this drug }\end{array}$ & $\begin{array}{c}\text { Question } \\
\text { not answered }\end{array}$ \\
\hline Anticoagulants (warfarin) & $20(9.3 \%)$ & $40(18.5 \%)$ & $144(66.7 \%)$ & $12(5.6 \%)$ \\
Antiplatelets & $76(35.2 \%)$ & $128(59.3 \%)$ & $8(3.7 \%)$ & $4(1.9 \%)$ \\
Antihypertensive agents & $16(7.4 \%)$ & $168(77.8 \%)$ & $24(11.1 \%)$ & $8(3.7 \%)$ \\
Lipid lowering drugs & $48(22.2 \%)$ & $156(72.2 \%)$ & $8(3.7 \%)$ & $4(1.9 \%)$ \\
Oral Hypoglycemic agents & $184(85.2 \%)$ & & $24(11.1 \%)$ & $8(3.7 \%)$ \\
Insulin & $188(87.0 \%)$ & & $24(11.1 \%)$ & $4(1.9 \%)$ \\
\hline
\end{tabular}


Table IV Model of factors influencing the knowledge about stroke/TIA risk factors

\begin{tabular}{|c|c|c|c|c|}
\hline \multirow[t]{2}{*}{ Factor } & \multirow[t]{2}{*}{ Odds ratio } & \multicolumn{2}{|c|}{ Confidence Interval } & \multirow[t]{2}{*}{ p-value } \\
\hline & & Lower limit & Upper limit & \\
\hline Age & 1.053175 & 1.007466 & 1.100958 & 0.022107 \\
\hline \multicolumn{5}{|l|}{ Sex } \\
\hline Male & 0.208729 & 0.040366 & 1.079303 & 0.061633 \\
\hline Female & 4.791784 & 0.926677 & 24.77799 & 0.061605 \\
\hline \multicolumn{5}{|l|}{ Address } \\
\hline Urban & 5.266551 & 1.864638 & 14.87503 & 0.001712 \\
\hline Rural & 0.189898 & 0.067237 & 0.536332 & 0.001713 \\
\hline \multicolumn{5}{|l|}{ Diagnosis } \\
\hline Cerebral infarction or Transient ischaemic attack & 4.637872 & 1.485285 & 14.48198 & 0.008268 \\
\hline Hemorrhagic stroke & 0.215624 & 0.069054 & 0.673297 & 0.00827 \\
\hline \multicolumn{5}{|l|}{ Monthly Income } \\
\hline$<20,000$ Taka & 0.154407 & 0.052865 & 0.450988 & 0.000635 \\
\hline$>20,000$ Taka & 6.477307 & 2.217573 & 18.91956 & 0.000635 \\
\hline \multicolumn{5}{|l|}{ Occupation } \\
\hline Housewife, Labour Work, Unemployed & 0.165092 & 0.039261 & 0.694217 & 0.013971 \\
\hline Business, Sedentary Work, Retired & 6.057181 & 1.440489 & 25.47013 & 0.01397 \\
\hline \multicolumn{5}{|l|}{ Education } \\
\hline SSC or below & 0.517868 & 0.203663 & 1.316814 & 0.16698 \\
\hline HSC or above & 1.931159 & 0.759467 & 4.910522 & 0.16693 \\
\hline Past history of stroke / TIA & 8.87098 & 2.628022 & 29.9443 & 0.000437 \\
\hline Family history of cardiovascular disease & 4.601226 & 1.836635 & 11.52721 & 0.001124 \\
\hline
\end{tabular}

Odds ratio $(\mathrm{OR})>1$ means that the factor is related to better knowledge, and $\mathrm{OR}<1$ to poorer knowledge. Results from ordered logistic regression analysis; Statistical significance at level: *) $\mathrm{p}<0.05 ; * *) \mathrm{p}<0.01 ; * * *) \mathrm{p}<0.001$.

Knowledge about treatment for reducing the risk of having a new stroke/TIA

Anticoagulants and antiplatelets are important drugs for stroke/TIA prevention but only 20(9.3\%) of the patients who reported anticoagulants and 76(35.2\%) of the patients taking these drugs marked them as intended for prevention. About three fourth of patients reported taking antihypertensive or Lipid lowering drugs them as intended for treatment. Surprisingly majority of those taking oral hypoglycemic agents/insulin marked them as intended for prevention (Table IV).

\section{DISCUSSION}

Our study showed that knowledge of stroke/TIA risk factors among patients varied. Some diseases/conditions (diabetes and hypertension)and lifestyle related factors (older age, smoking, regular exercise, overweight, suffering previous stroke/TIA) seemed to be quite well known stroke/TIA risk factors. Specific diseases such as carotid stenosis and atrial fibrillation were identified as risk factors to a lesser extent.

Diabetes mellitus and hypertension had the high identification rate. Poor understanding of the fact that diabetes could be a stroke/TIA risk factor was observed previously by Kraywinkel et al in a study conducted among people without prior stroke/TIA events ${ }^{23}$ and also in a study by Maasl and et al. ${ }^{24}$ In a study conducted in India, diabetes was among the best known stroke/ TIA risk factors, at the same level as hypertension, smoking which is similar to our study. ${ }^{25}$ This could be the result of more frequent contacts with medical care(because of regular monitoring and follow up of 
diabetic patients in BIRDEM General Hospital), or a particular interest in health issues, since these patients had probably received more detailed information regarding diabetes and hypertension. In the prevention and education of the diabetic patients, most focus tends to be on cardiovascular complications, complications from the eyes and the feet, and stroke related complications.

$81.5 \%$ of the patients could identify the fact that a previous event of stroke/TIA was a factor that increased the risk of having a new stroke/TIA which is similar to other studies. ${ }^{19}$ Patients in our study who had a registered diagnosis of cerebral haemorrhage had a lower level of knowledge about stroke/TIA risk factors, which might be due to worse clinical condition) that follows a haemorrhagic stroke as compared to an ischaemic stroke. ${ }^{26}$ Occasionally, a diagnosis of cerebral haemorrhage is used as exclusion criteria when studying knowledge about risk factors. ${ }^{28}$

In some studies, a number of socio demographic factors have been found to influence patients' knowledge about stroke/TIA risk factors; for example, older age, male sex, and lower educational level. ${ }^{27}$ Older age, patient residing in urban areas, patients of high income group, family history of cardiovascular disease have been identified to influence patients' knowledge about stroke/ TIA risk factors in our study. We found that being older is a factor that positively influenced knowledge of stroke/TIA risk factors. Higher age was found to have a negative effect in some studies ${ }^{19,27,28}$ but no effect in others. ${ }^{23}$ Lower educational level was found to have a negative effect in a study conducted in India ${ }^{25}$, but not in some other studies. ${ }^{23,}{ }^{27} \mathrm{We}$ also didn't find any significant effect of level of education.

Patients who are given anticoagulants or anti-platelets should be informed about the preventive effect of these drugs, and the fact that only $9.3 \%$ of those reporting the use of anticoagulants and $35.2 \%$ of those reporting the use of antiplatelets indicated that their purpose was preventive is worrying. The lower proportions for patients using antihypertensive, lipid lowering agents also indicate the importance of better patient education. It is a matter of good hope that patient taking oral hypoglycemic agents and insulin showed good knowledge as a preventive effect of these drugs. These results are similar to this study. ${ }^{29}$ Limitation of this study is small sample size and single center study.

\section{Conclusion}

Our study shows that knowledge about diabetes, hypertension and smoking as risk factors was good, and patients who suffered from atrial fibrillation or carotid stenosis seemed to be less informed about these conditions as risk factors. The knowledge level was low regarding the use of anticoagulants and antiplatelets for stroke/TIA prevention. We observed a better knowledge in our study population to some of the risk factors. However, it is suggested that, there is lacking in terms of knowledge of stroke patients about some other risk factors of stroke. This situation will adversely affect the potential to prevent the disease. Healthcare professionals especially those who are directly involved in the care of stroke patients must therefore be more cautious during patient education. Policymakers must see the situation as a call to action by putting in place necessary policies that will facilitate stroke education. Furthermore, individuals with little knowledge should be given special consideration when developing strategies and programmes thus improving awareness of stroke risk factors.

Authors' contributions: MRI drafted the protocol, collected data, did literature search and drafted the manuscript. TR performed the literature search and helped in drafting manuscript. RNI did statistical analysis. MSHK collected data. MI collected data. RH helped in preparation of manuscript and did literature search. All authors read and approved the final manuscript.

Conflict of interest: Nothing to declare.

\section{REFERENCES}

1. Zoghbi WA, Duncan T, Antman E, Barbosa M, Champagne $\mathrm{B}$, Chen D et al. Sustainable development goals and the future of cardiovascular health: a statement from the global cardiovascular disease taskforce.Journal of the American Heart Association. 2014; 3(5): e000504.

2. Mendis S, Davis S, Norrving B. Organizational update world health organization. Stroke 2014; 45(2):22-3.

3. Gwatkin DR, Bhuiya A, Victora CG. Making health systems more equitable. The Lancet 2004; 364(9441): 1273-80.

4. Islam MN, Moniruzzaman M, Khalil MI, Basri R, Alam MK, Loo KW et al. Burden of stroke in Bangladesh.International Journal of Stroke 2019: 8(3): 211-3.

5. Mohammad QD, Habib M, HoqueA, B Alam, B Haque, S Hossain, et al. Prevalence of stroke above forty years. Mymensingh Medical Journal. 2011; 20(4):640-4. 
6. Hossain A, Ahmed N, Rahman M, Islam M, Sadhya G, Fatema K. Analysis of sociodemographic and clinical factors associated with hospitalized stroke patients of Bangladesh. Faridpur Medical College Journal 2011; 6(1): 19-23.

7. Siddique MAN, Nur M, Mahbub S, Alam MB, Miah MT. Clinical presentation and epidemiology of stroke: a study of 100 cases. J Medicine 2009; 10(2):86-9.

8. Uddin MS, Mamun AA, Asaduzzaman M, Hosen F, Sufian MA, Taked S. Spectrum of Disease and Prescription Pattern for Outpatients with Neurological Disorders: An Empirical Pilot Study in Bangladesh. Annals of Neurosciences 2010; 74(2): 5-8.

9. Burn J, Dennis M, Bamford J, Sandercock P, Wade D, Warlow C. Long-term risk of recurrent stroke after a first-ever stroke. The Oxfordshire community stroke project. Stroke 1994; 25(2):333-7.

10. Moroney JT, Bagiella E, Paik MC, Sacco RL, Desmond DW. Risk factors for early recurrence after ischemic stroke: the role of stroke syndrome and subtype.Stroke 1998; 29(10): 2118-24.

11. Flemming KD, Brown RD. Secondary prevention strategies in ischemic stroke: identification and optimal management of modifiable risk factors. Mayo Clinic Proceedings 2004; 79(10): 1330-40.

12. Prabhakaran S, Chong JY. Risk factor management for stroke prevention. CONTINUUM: Lifelong Learning in Neurology 2014; 20(2): 296-308.

13. Glader EL, Stegmayr B, Norrving B, Terent A, Hulter-Asberg $\mathrm{K}$, Wester $\mathrm{PO}$ et al. Large variations in the use of oral anticoagulants in strokepatients with atrial fibrillation: a Swedish national perspective. J InternMed 2004; 255(1):2232 .

14. Girot M, Mackowiak-Cordoliani MA, Deplanque D, Henon $\mathrm{H}$, Lucas C, Leys D.Secondary prevention after ischemic stroke. Evolution over time inpractice.J Neurol2005; 252(1):14-20.

15. Croquelois A, Bogousslavsky J. Risk awareness and knowledge of patients with stroke: results of a questionnaire survey 3 months after stroke. Journal of Neurology, Neurosurgery and Psychiatry 2006; 77(6):726-8.

16. O'Mahony PG, Rodgers H, Thomson RG, Dobson R, James OF. Satisfaction with information and advice received by stroke patients.ClinRehabil1997, 11(1):68-72.
17. Blades LL, Oser CS, Dietrich DW, Okon NJ, Rodriguez DV, Burnett AM et al. Rural community knowledge of stroke warning signs and risk factors. Preventing Chronic Disease 2005; 2(2):A14.

18. Ferris A, Robertson RM, Fabunmi R, Mosca L.American Heart Association and American Stroke Association national survey of stroke risk awareness among women. Circulation 2005; 111(10):1321-6.

19. Kothari R, Sauerbeck L, Jauch E, Broderick J, Brott T, Khoury et al. Patients' awareness of stroke signs, symptoms, and risk factors. Stroke 1997; 28(10):1871-5.

20. Pancioli AM, Broderick J, Kothari R, Brott T, Tuchfarber A, Miller R, et al.Public perception of stroke warning signs and knowledge ofpotential risk factors. The Journal of the American Medical Association1998; 279 (16):1288-92.

21. Gupta A, Thomas P.General perception of stroke. Knowledge of stroke is lacking. British Medical Journal 2002; 325(7360):392.

22. Samsa GP, Cohen SJ, Goldstein LB, Bonito AJ, Duncan PW, Enarson $\mathrm{C}$ et al. Knowledge of risk among patients at increased risk for stroke.Stroke 1997;28(5):916-21.

23. Kraywinkel K, Heidrich J, Heuschmann PU, Wagner M, Berger K. Stroke risk perception among participants of a stroke awareness campaign. BMC Public Health 2007; 7:39.

24. Maasl and L, Koudstaal PJ, Habbema JDF, Dippel DWJ. Knowledge and Understanding of Disease Process, Risk Factors and Treatment Modalities in Patients with a Recent TIA or Minor Ischemic Stroke. Cerebrovasc Diseases 2007; 23:435-40.

25. Das K, Mondal GP, Dutta AK, Mukherjee B, Mukherjee BB. Awareness of warning symptoms and risk factors of stroke in the general population and in survivors stroke. J ClinNeurosci2007; 14(1):12-6.

26. Ferro JM, Canhao P, Peralta R. Update on subarachnoid haemorrhage. J Neurol 2008; 255(4):465-79.

27. Koenig KL, Whyte EM, Munin MC, O’Donnell L, Skidmore ER, Penrod LE et al. Stroke-related knowledge and health behaviors among post stroke patients in inpatient rehabilitation. Arch Phys Med Rehabil 2007; 88(9):1214-6.

28. Samsa GP, Cohen SJ, Goldstein LB, Bonito AJ, Duncan PW, Enarson $\mathrm{C}$ et al. Knowledge of risk among patientsat increased risk for stroke. Stroke 1997; 28(5):916-21.

29. Sloma A, Backlund LG, Strender L, Skånér Y. Knowledge of stroke risk factors among primary care patients with previous stroke or TIA: a questionnaire study. BMC Family Practice 2010; 11:47. 